\title{
Understanding, Perception and Prevalence of Plagiarism among College Freshman Students of De La Salle Lipa, Philippines
}

\author{
Jose Macatangay
}

\begin{abstract}
The study investigated the relationship between understanding and prevalence of plagiarism, perceived seriousness and prevalence of plagiarism as well as understanding and perceived seriousness of plagiarism when college freshman students of De La Salle Lipa, Philippines were grouped according to academic disciplines. It was hypothesized in the study that as level of understanding and perceived seriousness of plagiarism increased the tendency to commit it decreased. An adopted self-report questionnaire which contained six scenarios covering the six different types of plagiarism was answered by the respondents. Though with low and negligible correlation, study revealed some trends on relationship between the students' understanding of plagiarism and its degree of seriousness as well as on students' understanding of plagiarism and frequency of its occurrence. Results of the study may be useful for enhancing current academic practices and for revisiting institutional policy on plagiarism.
\end{abstract}

Index Terms-Plagiarism, prevalence, seriousness, understanding.

\section{INTRODUCTION}

Pavela [1] classified academic dishonesty as cheating which is an intentional use of unauthorized materials in any academic exercise; fabrication which is an intentional falsification of any information in an academic exercise and plagiarism which is an intentional use of the ideas of another as one's own in any academic exercise. The third classification of academic dishonesty is the emphasis of this paper.

Through the years, plagiarism remains an issue of concern among academic institutions. For students, unfamiliarity with what constitutes plagiarism is the most consistent reason for committing it. It then follows that lack of understanding of plagiarism means difficulty recognizing its various forms along with the degree of its seriousness.

There are seven types of plagiarism according to Walker [2]: sham paraphrasing, illicit paraphrasing, other plagiarism, verbatim copying, recycling, ghost writing, and purloining. When a material is copied verbatim from text and the source is acknowledged in-line but is represented as a paraphrase, it is called sham paraphrasing as opposed to illicit paraphrasing where the material is paraphrased but without in-line acknowledgment of the source. Other plagiarism is copying from another student's assignment with the permission of the

Manuscript received May 8, 2014; revised July 10, 2014

Jose Macatangay is with the De La Salle Lipa, Philippines (e-mail: jose.macatangay@dlsl.edu.ph). owner while purloining is also copying from the work of others without permission. Verbal copying is when a material is copied exactly from the source without any acknowledgement. Recycling as a type of plagiarism happens when the student submits the same assignment more than once for different courses. An assignment written by a third party and represented as own work is called ghost writing.

Based on North American experience, Park [3] reviewed the literatures on plagiarism by students. Through the review he made, he found that there were "multiple reasons" why students plagiarized. The genuine lack of understanding proper ways of "quoting, paraphrasing, citing and referencing" may lead students to plagiarize. Another reason mentioned was the improper time management of students who have an active social life, tedious academic deadlines and taxing family pressures that do not give them ample time to finish their assignments so they fall into the trap of plagiarism. The accessibility of online information makes students so vulnerable to plagiarism because of the convenience it brings known as "temptation and opportunity" for falling into the trap of plagiarism.

Different measures done by several universities in the United States and in the United Kingdom to address plagiarism were reported by Maurer [4] in their study.

At the Standford University, the Standford Honor Code specified the standard penalty for a first offense of any academic misconduct which includes a one-quarter suspension from the university and a 40-hour community service. For multiple violations, a three-quarter suspension and a 40 or more hours of community service is to be sanctioned to the offenders.

The Yale University showed "great concern about increase in web plagiarism" where punishments depending on the gravity of the case vary from reprimands to suspension. In the university, teachers are expected to integrate in their lessons citation rules and writing styles that will help students avoid plagiarism.

At Oxford, there is the Court of Summary Justification which decides on plagiarism related cases while at Cambridge, proctors, university advocates and disciplinary elements decide on the sanctions based on the recommendations of the examiners. Suspected plagiarism cases at Cambridge were dealt with separately based on academic and disciplinary elements.

Arbib and Yaari [5] examined students' perceptions toward acts of plagiarism. The study aimed to explore whether plagiarism from internet sources is perceived differently by the respondents than plagiarism from printed sources. Results of the study offered empirical evidence on 
the different perceptions on internet and printed sources plagiarism. Administered to 284 students, findings of the study confirmed that the respondents perceived plagiarism from internet sources to be less dishonest as compared to the act of plagiarism using a printed source. In the study, the participant's age was found to have an influence on their perceptions on the item "ideas without of the author's name" related to printed sources.

To investigate ethical perceptions of students in higher academic institutions and to examine the differences in their perceptions of the seriousness and academic misconduct according to gender and ethnicity, Peled [6] conducted a study to 153 participants from three Israeli academic institutes in Norhern Israel. The study revealed that the respondents considered "Copying from someone else during a test" to be the most serious type of academic misconduct while "Not contributing to the group's work in a group assignment as the least serious. Respondents differed according to course type, gender and ethnicity in their perceptions of academic misconduct.

In her dissertation, Bens [7] studied five groups of senior Education students' from two western Canadian universities on their understanding of academic honesty and dishonesty. Using a naturalistic research design where data were the verbatim discussions of the respondents, the researcher found that existence of rules, intent to break the rules and unearned great advantages to be the elements considered important by the students in their understanding of academic dishonesty. The elements were extrapolated to develop a baseline definition of academic dishonesty. Roles of students such as subject, moral agent, trainee and competitor in relation to academic dishonesty were also identified.

Maxwell et.al [8] delved into the influence of culture on understanding and perceived seriousness of plagiarism. They compared local and Asian international students enrolled in two Australian universities using the self-report questionnaire presenting the seven types of plagiarism. No differences were found between the two groups of respondents in ratings of perceived seriousness and understanding of plagiarism. This means that culture may not be a factor that affects understanding and perception of students on plagiarism. However, significant negative relationships were revealed between both seriousness and understanding of self-report plagiarism rates which is suggestive of the fact that "as perceived seriousness and understanding of plagiarism decreases, rates of plagiarism increase."

The De La Salle Lipa College Student Handbook [9] defines plagiarism as "the act or instance of stealing and passing of the ideas or works of another as one's own without crediting the sources ; and taking someone's words or ideas as they were as your own." Plagiarism is considered a form of cheating under Category 2 offenses which could lead to "dismissal, non-readmission, expulsion, or exclusion of the offender as may be determined by the Discipline Board." Noteworthy, plagiarism in the student handbook is treated in three separate ways: first, as a definition, second as a form of cheating and third as an Appendix titled Academic Dishonesty.

Interestingly, the school has a clear sanction as to any incidence of plagiarism but has no home grown or original clear-cut rules, guidelines or policies about it. This is similar to some research findings from the USA and the UK showing that student plagiarism in universities is on its rise due to the lack of policies focused on curbing it.

The study aims to compare across academic disciplines of the College of Education Arts and Sciences of De La Salle Lipa the students' understanding, perception and prevalence of plagiarism. Specifically, the study seeks to answer the following questions:

1) What are the academic disciplines of the respondents?

2) Given some scenarios on plagiarism.

- What are the respondents' ratings of each scenario?

- What is the respondents' perceived seriousness on the identified type of plagiarism?

3) When grouped according to academic disciplines, is there a significant relationship between the respondents' understanding of plagiarism and frequency of plagiarism;

- Perceived seriousness of plagiarism and frequency of plagiarism;

- Understanding and perceived seriousness of plagiarism?

\section{Methodology}

The input component of the study included the academic disciplines of the respondents. The research process was pursued through the adopted self-report questionnaire. The modified questionnaire included six scenarios that the respondents had to answer based on their understanding and perceived seriousness of the given scenario. Ultimately, the results of the study can serve as basis/input for integration in the College Student Handbook of De La Salle Lipa. Likewise, the integration of understanding plagiarism as a lesson on Academic and Research Writing classes can be further enhanced for students to have better understanding of plagiarism.

Descriptive research method was applied in conducting the study. According to Best and Kahn [10], descriptive research employs the process of disciplined inquiry through the gathering and analysis of empirical data in order to develop knowledge through the expertise of the investigator. In order to describe and interpret clearly the prevailing conditions and situations related to the study, a comparative research design was designed. The study compared across disciplines in the College of Education Arts and Sciences of De La Salle Lipa, the respondents' understanding and perception of plagiarism in order to determine if they differ significantly.

The respondents were college freshman students enrolled in Communication Skills 2 during the second semester of the academic year 2013-2014. The respondents were grouped systematically according to their academic disciplines classified as: AB Communication, BS Biology, BS Education, AB MMA, and BS Psychology.

To assess the respondents' understanding of plagiarism, the question "Do you consider this to be plagiarism?" was found after each scenario. The respondents ticked "Yes", "No" and "I don't know" based on the applicability of the question to them. Perceived seriousness was determined 
through the question "How serious do you think this is?" In order to measure the prevalence of plagiarism, the question "Have you ever done a similar thing?" was provided after each scenario and was responded through a 5-point scale: 1-never, 2-once only, 3- two-three times, and 4-four to seven times and 5- more than seven times.

Data gathered from the study were analyzed using descriptive statistics such as frequency percentage, mean determination and pearson r-correlation. Frequency percentage was used to determine the respondents' understanding of plagiarism. Mean determination was used to measure the respondents' perceived seriousness and prevalence of plagiarism. Pearson r-correlation was used to relate the students' understanding of plagiarism to their perceived seriousness of it. The same statistical tool was used to relate the students' understanding of plagiarism to the frequency of committing it.

\section{RESULTS AND DisCUSSIONS}

\section{A. Understanding of Plagiarism}

Table I depicts the respondents' understanding of plagiarism.

Three groups of respondents, AB Communication, BS Education and AB MMA recognized "verbatim copying" as the topmost type of plagiarism they understood. Verbal copying is when a material is lifted from a source without acknowledging it. The case given to the respondents was "A student copies word for word information from a book. She does not put the information in quotation marks. She also does not write the author, date of publication or page number at the end of the copied material." Following the scenario was the question: "Do you consider this to be plagiarism?"

Both BS Biology and BS Psychology, got the highest percentage on purloining which is $96 \%$ and $98 \%$ respectively. Respondents from both disciplines considered copying the work of a classmate without permission to be the leading type of plagiarism they understood.

TABLE I: RESPONDENTS' UNDERSTANDING OF PLAGIARISM

\begin{tabular}{|c|c|c|c|c|c|}
\hline $\begin{array}{ll}\text { Type } & \text { of } \\
\text { plagiarism } & \\
\end{array}$ & ABCOMM & BSBIO & BSEDUC & $\begin{array}{l}\text { AB } \\
\text { MMA }\end{array}$ & $\begin{array}{l}\mathrm{BS} \\
\mathrm{PSYCH}\end{array}$ \\
\hline $\begin{array}{l}\text { Sham } \\
\text { plagiarism }\end{array}$ & $46 \%$ & $46 \%$ & $68 \%$ & $44 \%$ & $45 \%$ \\
\hline $\begin{array}{l}\text { Other } \\
\text { plagiarism }\end{array}$ & $70 \%$ & $71 \%$ & $93 \%$ & $72 \%$ & $91 \%$ \\
\hline $\begin{array}{l}\text { Verbatim } \\
\text { copying }\end{array}$ & $95 \%$ & $93 \%$ & $96 \%$ & $94 \%$ & $94 \%$ \\
\hline Ghost writing & $73 \%$ & $54 \%$ & $71 \%$ & $59 \%$ & $81 \%$ \\
\hline $\begin{array}{l}\text { Illicit } \\
\text { paraphrasing }\end{array}$ & $65 \%$ & $29 \%$ & $50 \%$ & $28 \%$ & $81 \%$ \\
\hline Purloining & $78 \%$ & $96 \%$ & $89 \%$ & $78 \%$ & $98 \%$ \\
\hline
\end{tabular}

Three groups of respondents BS Biology, BS Education and $\mathrm{AB}$ MMA got the lowest percentage on "illicit paraphrasing" while the two groups, AB Communication and BS Psychology had their lowest score on "sham paraphrasing." Sham paraphrasing is when the source is acknowledged but the material is still copied verbatim from the text while illicit paraphrasing is done similarly only that the source is not acknowledged. Differences in percentages could be attributed to their understanding or misunderstanding of plagiarism.

\section{B. Perceived Seriousness of Plagiarism}

Table II presents the respondents' perception of each type of plagiarism.

It can be gleaned from the table that the groups' understanding of the type of plagiarism jives with their perceived seriousness of it. Since verbatim copying was considered by respondents from $\mathrm{AB}$ Communication, BS Education and $\mathrm{AB}$ MMA to be the type of plagiarism they highly understood, they also perceived it to be the most serious. In the same vein, since BS Biology and BS Psychology respondents understood purloining as the highest form of plagiarism, they perceived it to be the most serious.

\begin{tabular}{llllll}
\multicolumn{5}{c}{ TABLE II: RESPONDENTS' PERCEPTION OF PLAGIARISM } \\
\hline \hline $\begin{array}{l}\text { Type } \\
\text { plagiarism }\end{array}$ & ABCOMM & BSBIO & BSEDUC & $\begin{array}{l}\text { AB } \\
\text { MMA }\end{array}$ & $\begin{array}{l}\text { BS } \\
\text { PSYCH }\end{array}$ \\
\hline $\begin{array}{l}\text { Sham } \\
\text { plagiarism }\end{array}$ & 2 & 1.8 & 2.0 & 2.1 & 2.0 \\
$\begin{array}{l}\text { Other } \\
\text { plagiarism }\end{array}$ & 2.3 & 2.4 & 2.3 & 2.5 & 2.8 \\
$\begin{array}{l}\text { Verbatim } \\
\text { copying }\end{array}$ & $\mathbf{2 . 7}$ & 2.8 & $\mathbf{2 . 7}$ & $\mathbf{2 . 6}$ & 2.7 \\
$\begin{array}{l}\text { Ghost writing } \\
\text { Illicit }\end{array}$ & 2.5 & 2.2 & 2.3 & 2.3 & 2.5 \\
paraphrasing & 2.1 & 1.7 & 1.9 & 2.0 & 2.1 \\
Purloining & 2.5 & $\mathbf{2 . 9}$ & 2.5 & 2.5 & $\mathbf{2 . 8}$ \\
\hline \hline
\end{tabular}

\section{Prevalence of Plagiarism}

Table III shows the frequency of plagiarism committed by the respondents.

Summing up the results of the two tables, it can be gleaned that the groups' understanding of plagiarism is consistent with their perceived seriousness of it. Verbatim copying was the type of plagiarism understood and considered very serious by three groups of respondents followed by purloining identified to be very serious by two groups of respondents. Indeed, as one fully understands what plagiarism is, he/she tends to attach a degree of seriousness to a particular type of plagiarism.

TABLE III: RESPONDENTS’ PREVALENCE OF COMMITTING PLAGIARISM

\begin{tabular}{llllll}
\hline $\begin{array}{l}\text { Type of } \\
\text { plagiarism }\end{array}$ & ABCOMM & BSBIO & BSEDUC & $\begin{array}{l}\text { AB } \\
\text { MMA }\end{array}$ & $\begin{array}{l}\text { BS } \\
\text { PSYCH }\end{array}$ \\
\hline $\begin{array}{l}\text { Sham } \\
\text { plagiarism }\end{array}$ & $\mathbf{3 . 2}$ & $\mathbf{3 . 1}$ & $\mathbf{2 . 8}$ & $\mathbf{3 . 2}$ & $\mathbf{3 . 1}$ \\
$\begin{array}{l}\text { Other } \\
\text { plagiarism }\end{array}$ & 2.2 & 1.4 & 1.5 & 1.6 & 1.5 \\
$\begin{array}{l}\text { Verbatim } \\
\text { copying }\end{array}$ & 2.1 & 2.3 & 2.2 & 2.1 & 2.1 \\
$\begin{array}{l}\text { Ghost } \\
\text { recycling }\end{array}$ & $\mathbf{1 . 3}$ & $\mathbf{1 . 1}$ & $\mathbf{1 . 2}$ & $\mathbf{1 . 2}$ & $\mathbf{1 . 1}$ \\
$\begin{array}{l}\text { Illicit } \\
\text { paraphrasing }\end{array}$ & 2.4 & 3.4 & 2.2 & 2.6 & 2.4 \\
Purloining & 1.5 & 1.1 & 1.3 & 1.5 & 1.1 \\
\hline
\end{tabular}

In response to the third question "Have you ever done a similar thing?" all four groups of respondents were unanimous in their answer that they have never committed ghost writing as demonstrated by the lowest mean determination falling on the scale 1.0-1.49 and verbally interpreted as never. Both BS Biology and BS Psychology were never into ghost writing and purloining as revealed by the similar scores they gave for both types of plagiarism. As 
for the most frequent type of plagiarism commonly committed, the four groups were undisputed on their claim that they were guilty of sham paraphrasing.

\section{Relationship between Understanding and Prevalence of Plagiarism}

Table IV presents significant relationship was found between understanding and frequency of plagiarism among Psychology students. All the rest of the programs show no significant relationship.

By using Pearson's correlation coefficient, $r=-0.229$ verbally interpreted as negative low correlation, significance was found between students' understanding and frequency of plagiarism. Analysis implies that one's understanding of what constitutes plagiarism may somehow lessen his/her tendency to commit it.

TABLE IV: RELATIONSHIP BETWEEN UNDERSTANDING OF PLAGIARISM AND FREQUENCY OF PLAGIARISM ACCORDING TO STUDENTS' ACADEMIC DISCIPLINES

\begin{tabular}{|c|c|c|c|c|c|}
\hline Program & $N$ & $\begin{array}{c}\text { Correlation } \\
\text { Coefficient }\end{array}$ & $\begin{array}{c}\text { Verbal } \\
\text { Interpretation }\end{array}$ & $\begin{array}{c}P \\
\text { value } \\
\end{array}$ & Significance \\
\hline Education & 28 & -0.308 & $\begin{array}{l}\text { Negative, Low } \\
\text { correlation }\end{array}$ & 0.110 & $\begin{array}{c}\text { Not } \\
\text { Significant }\end{array}$ \\
\hline MMA & 32 & -0.187 & $\begin{array}{l}\text { Negative, } \\
\text { Negligible } \\
\text { correlation }\end{array}$ & 0.306 & $\begin{array}{c}\text { Not } \\
\text { Significant }\end{array}$ \\
\hline ABComm & 37 & -0.020 & $\begin{array}{l}\text { Negative, } \\
\text { Negligible } \\
\text { correlation }\end{array}$ & 0.908 & $\begin{array}{c}\text { Not } \\
\text { Significant }\end{array}$ \\
\hline Psychology & 53 & -0.376 & $\begin{array}{c}\text { Negative, Low } \\
\text { correlation }\end{array}$ & 0.006 & Significant \\
\hline Biology & 28 & -0.103 & $\begin{array}{l}\text { Negative, } \\
\text { Negligible } \\
\text { correlation }\end{array}$ & 0.603 & $\begin{array}{c}\text { Not } \\
\text { Significant }\end{array}$ \\
\hline CEAS & $\begin{array}{c}17 \\
8\end{array}$ & -0.229 & $\begin{array}{l}\text { Negative, Low } \\
\text { correlation }\end{array}$ & 0.002 & Significant \\
\hline
\end{tabular}

\section{E. Relationship between Perceived Seriousness and Prevalence of Plagiarism}

Table V depicts relationship between perceived seriousness and frequency of plagiarism by respondents' academic disciplines. Significant relationship was revealed only in the Psychology Program. No significant relationship was discovered in all other programs.

TABLE V: RELATIONSHIP BETWEEN STUDENTS' PERCEIVED SERIOUSNESS OF PLAGIARISM AND FREQUENCY OF PLAGIARISM ACCORDING TO STUDENTS' ACADEMIC DISCIPLINES

\begin{tabular}{|c|c|c|c|c|c|}
\hline Program & $N$ & $\begin{array}{c}\text { Correlation } \\
\text { Coefficient }\end{array}$ & $\begin{array}{c}\text { Verbal } \\
\text { Interpretation }\end{array}$ & $\begin{array}{c}P \\
\text { value }\end{array}$ & Significance \\
\hline Education & 28 & 0.122 & $\begin{array}{l}\text { Positive, } \\
\text { Negligible } \\
\text { correlation }\end{array}$ & 0.537 & $\begin{array}{c}\text { Not } \\
\text { Significant }\end{array}$ \\
\hline MMA & 32 & -0.226 & $\begin{array}{l}\text { Negative, Low } \\
\text { correlation }\end{array}$ & 0.213 & $\begin{array}{c}\text { Not } \\
\text { Significant }\end{array}$ \\
\hline ABComm & 37 & -0.174 & $\begin{array}{l}\text { Negative, } \\
\text { Negligible } \\
\text { correlation }\end{array}$ & 0.302 & $\begin{array}{c}\text { Not } \\
\text { Significant }\end{array}$ \\
\hline Psychology & 53 & -0.351 & $\begin{array}{l}\text { Negative, Low } \\
\text { correlation }\end{array}$ & 0.010 & Significant \\
\hline Biology & 28 & -0.035 & $\begin{array}{l}\text { Negative, } \\
\text { Negligible } \\
\text { correlation }\end{array}$ & 0.859 & $\begin{array}{c}\text { Not } \\
\text { Significant }\end{array}$ \\
\hline CEAS & $\begin{array}{c}17 \\
8\end{array}$ & -0.186 & $\begin{array}{l}\text { Negative, } \\
\text { Negligible } \\
\text { correlation }\end{array}$ & 0.013 & Significant \\
\hline
\end{tabular}

By using Pearson's correlation coefficient, $r=-0.186$, negligible correlation was found between students' perceived seriousness of plagiarism and the prevalence of committing it. Such trend reveals that no matter how serious the case of plagiarism may be, the tendency to commit is always there. Table V encapsulates the result.

\section{CONCLUSION AND DIRECTIONS FOR FUTURE RESEARCH}

The respondents of the study were enrolled in $\mathrm{AB}$ Communication, BS Biology, BS Education, AB Multimedia Arts, and BS Psychology. They rated verbatim copying as the type of plagiarism they understood highly and this was followed by purloining.

The respondents' highest self-rating of the types of plagiarism they understood was also what they considered to be the most serious. In other words, understanding of the type of plagiarism was congruent with the degree of its seriousness as perceived by the respondents. Since verbatim copying and purloining were highly understood by the respondents, they also considered those types of plagiarism to be the most serious.

When treated according to academic disciplines, it was only in the Psychology Department where significance between understanding and frequency of plagiarism was found with a negligible correlation. Negative low correlation could mean there is a relationship between students' knowledge of plagiarism and their frequency of committing it though at a very low level.

However, when treated as a whole, this means all the five programs of the College of Education Arts and Sciences of De La Salle Lipa, a negligible correlation was found between students' perceived seriousness of plagiarism and its frequency. Negligible correlation could mean a very thin or almost no relationship existed between the variables studied and compared.

Although the study was conducted with a small sample size, the results somehow confirm the fact that as understanding and perceived seriousness of plagiarism increases, the tendency to commit it is likely to lessen.

The results of the study have implications for both institutional policy and educational practices. For institutional policy, results may be used for designing a more relevant or clear-cut plagiarism policies for integration in the student handbook. As for educational practices, lessons on referencing, citations, paraphrasing and summarizing need to be reinforced in Academic and Research Writing classes. Giving students scenarios to classify whether plagiarized or not can be a good practice in order to gauge their understanding of plagiarism. The current practice of matching the student's research paper through the school-purchased software known as TURNITIN can be continued to impress on students the school's advocacy for intellectual honesty.

Future researchers can replicate the study by using a bigger sample size (across colleges) to fully establish if there really exists significant relationship between understanding and seriousness of plagiarism as well as between understanding and frequency of plagiarism. The low correlation and negligible correlation obtained from the study may be attributed to small sample size. 
A comparative study on the understanding and perceptions of plagiarism can be done on other variables such as gender and country of origin (e.g. Filipino students' vs foreign students) understanding and perception of plagiarism.

\section{REFERENCES}

[1] G. Pavela. (1997). Applying the power of association on campus: a model code of academic integrity. [Online]. Available: http://www.integrityseminar.org/sites/default/files/pdfs/Mode1\%20Co de\%20of\%20Academic\%20Integrity.pdf

[2] J. Walker. (1998). Student plagiarism in universities: What are we doing about it. [Online]. Available: http://www.tandfonline.com/doi/pdf/10.1080/0729436980170105

[3] C. Park. (2003). In other people's words: plagiarism by university students-literature and lessons. [Online]. Available: http://dutmoodle.dut.ac.za/moodle/pluginfile.php/30664/mod_resourc e/content///In_other_people_s_words_plagiarism_by_university_stud ents_-_literature_and_lessons.pdf

[4] H. Maurer, F. Kappe, and B. Zaka. (2006). Plagiarism - a survey. Journal of Universal Computer Science. [Online]. Available: http://citeseerx.ist.psu.edu/viewdoc/download?doi=10.1.1.102.5629\& rep=rep $1 \&$ type $=$ pdf

[5] S. Arbib and E. Yaari. (2004). Printed versus internet plagiarism: a study of students' perception. International Journal of Information Ethics. [Online]. Available: http://container.zkm.de/ijie/ijie/no001/ijie_001_05_baruchson.pdf

[6] Y. Peled, Y. Eshet, and K. Grinautski. (2013). Perceptions regarding the seriousness of academia dishonesty amongst students-a comparison between face-to-face and online courses. [Online]. Available: http://www.openu.ac.il/innovation/chais2013/download/c1_3.pdf
[7] S. Bens. (2010). Senior education students' understandings of academic honesty and dishonesty. [Online]. Available: http://ecommons.usask.ca/bitstream/handle/10388/etd-09192010-1541 27/dissertation.pdf

[8] A. Maxwell, G. J. Curtis, and L. Vardanega. (2008). Does culture affect understanding and perceived seriousness of plagiarism. [Online]. Available:

http://www.ojs.unisa.edu.au/index.php/IJEI/article/viewFile/412/292

[9] De La Salle College Student Handbook, 2013.

[10] J. Best and J. Kahn, Research in Education, New Delhi, India: Printice Hall, 2007.

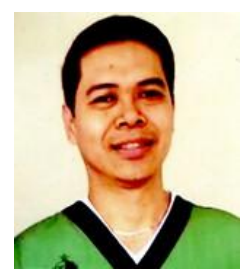

Jose C. Macatangay was born in Batangas City, Philippines on February 19, 1971. He is currently pursuing $\mathrm{PhD}$ in education major in English at the University of Batangas. He finished master of arts in teaching at the Philippine Normal University and bachelor of elementary education at Western Philippine Colleges.

$\mathrm{He}$ is currently connected at De La Salle Lipa Philippines where he serves as a faculty member teaching professional and major courses in education. His paper unpacking task components of DepEd's K to 12 learning package in English for grade VII is published in DLSL journal of multidisciplinary research. His research interests include discourse / genre analysis, ELT pedagogy and literary criticism.

Prof. Macatangay was the recipient of De La Salle Lipa outstanding research productivity award for two academic school years 2008-2009 and 2009-2010. 